\title{
Second edition of the international symposium on renewable energy and sustainability (ISRES 2013)
}

\author{
Xavier Mathew $\cdot$ Edgar Santoyo
}

Published online: 19 October 2014

(C) Springer Science+Business Media New York 2014

In commemoration of the 2012 international year of sustainable energy for all, declared by United Nations, and also for promoting the use of renewable energy (RE) and sustainability strategies, the Instituto de Energías Renovables of the Universidad Nacional Autónoma de México (IER-UNAM; formerly Centro de Investigación en Energía, CIE-UNAM) organized the second edition of the International Symposium on Renewable Energy and Sustainability (ISRES 2013). The symposium was organized at the campus of the IER-UNAM in Temixco, Morelos, Mexico; during 20-22 March, 2013. The scope of the symposium covered advances related to the RE development and sustainability, together with future opportunities, scientific-innovation challenges and training of human resources (mainly through graduate programs of the Mexican universities).

International experts from USA, Mexico, Switzerland, United Kingdom and Canada participated as speakers with a wide variety of topics related with RE and sustainability, among which solar thermal, solar photovoltaics, capacitors, wind, geothermics, bio-energy, energy saving in buildings, among others.
Two intensive days of the symposium covered plenary and poster sessions, and it was an excellent opportunity for the graduate students to develop their passion for clean and sustainable energies. Two main areas of the RE and sustainability were considered in the symposium; one of these was focused on the area of materials for RE applications, and the other one oriented to present original research on RE devices (current scenarios of the RE in Mexico and the worldwide, experimental design of prototypes,) and applications (software development, numerical simulation, etc.).

This special issue is specifically dedicated to the area of materials for RE applications, giving emphasis to material development efforts at various Institutes, Research Centers and Universities in Mexico. We want to thank Prof. Arthur Willoughby, Prof. Safa Kasap and the Editorial Staff of JMSE for their support and encouragement in bringing out this special issue. We are also grateful to the many materials scientists who served as reviewers, sparing their valuable time and providing critical comments, which we believe that enhanced the scientific merits of each paper finally approved for publication.

\footnotetext{
X. Mathew $(\bowtie) \cdot$ E. Santoyo

Instituto de Energías Renovables, Universidad Nacional

Autónoma de México, 62580 Temixco, Morelos, Mexico

e-mail: xm@ier.unam.mx

URL: http://www.ier.unam.mx

E. Santoyo

e-mail: esg@ier.unam.mx
} 